\title{
Assessment of nutrient and sediment loads in the Yarra River Catchment
}

\author{
$\underline{\text { S.K. Das }}{ }^{a}$, A.W.M. Ng ${ }^{\text {a }}$ and B.J.C. Perera ${ }^{b}$ \\ ${ }^{a}$ School of Engineering and Science, Victoria University, Melbourne 14428, AUSTRALIA \\ ${ }^{b}$ Faculty of Health, Engineering and Science, Victoria University, Melbourne 14428, AUSTRALIA \\ Email: sushilkumar.das@live.vu.edu.au
}

\begin{abstract}
Excessive loadings of non-point source pollution from different landuse activities cause eutrophication in rivers and creeks, and are a major concern to water resource managers. Catchment-scale management programs have been proven to be efficient in reducing water pollution from landuse activities. Understanding the connection between landuse activities and water quality is important for developing these management programs. However, the lack of knowledge of nutrient and sediment mass loads and their correlation with landuses are major impediments in applying these management programs. The main objective of this study was to assess nutrient and sediment loads at various sections of the Yarra River catchment in Victoria, Australia for the period of 1998-2009, and to investigate the correlation between these loads and different landuse types. The specific objectives were to: (1) establish whether there is a statistically significant difference between concentrations in water quality samples representing two flow regimes i.e. baseflow conditions and surface runoff events, (2) estimate pollutant mass load: nutrients and sediment at various sections of the catchment, and (3) identify the significant and major sources of pollutant loads.
\end{abstract}

A generic methodology was applied to achieve the above objectives using long-term in-stream water quality data and other readily available tools, which is also applicable to other catchments containing different landuses. The proposed methods and techniques addressed the issues of selecting water quality stations, catchment subdivision, identification of major landuse types, analysis of different flow regimes, and suitable methods to estimate loadings from the catchments containing different landuses. Although the methodology does not indicate the specific mechanisms causing surface runoff and pollutant transport, the data-based model is simple to apply and leads to good results, particularly in circumstances where limited time and data are available for assessment. In this study, 12 water quality stations were selected representing the Yarra River and its major tributaries of which 5 stations were on the main stem of the Yarra River. The dominant landuse type in the tributary stations was either agriculture or urban where as in the main stem stations; it was forest-agriculture mix type. Hydrograph separation allowed the separation of the water quality data into that collected during baseflow condition and surface runoff event. Baseflow conditions were defined as those water quality data collected when baseflow discharge was greater than or equal to $70 \%$ of mean daily discharge (total streamflow), and surface runoff events were defined as those data collected when baseflow discharge was less than $70 \%$ of mean daily discharge. The terms "baseflow conditions" and "surface runoff events" will be referred as "baseflow" and "events" respectively.

At all water quality stations, the pollutant concentrations were significantly $(p \leq 0.01)$ greater in events than in baseflow. Total nitrogen (TN), total phosphorus (TP) and total suspended solid (TSS) loads delivered during events at all main stem stations were on average 49,54 and 64 percent of the total loads respectively, where events were only on average 18 percent during the study period. On the other hand, the runoff loads for TN, TP and TSS at the tributary stations were on average 79,81 and 91 percent respectively, where events were on average 31 percent only. In each case, larger portion of pollutant loads delivered by events evidenced that major pollutant loads were generated from agricultural and urban runoff (i.e., non-point sources).

These results are encouraging especially given the pressing need to identify appropriate management practices to improve the water quality within the catchment. Overall, water quality and pollutant concentrations were influenced by flow regimes and landuse types, demonstrating the need for water quality monitoring programs to specifically target the collection of water quality samples during events and to characterize the distribution of constituent values in each flow condition of the Yarra River. The presence of increasing nutrient and sediment concentrations during events suggests that Yarra River catchment managers should focus on potential non-point sources that occur during events in streams.

Keywords: Pollutant concentrations and loads, Baseflow conditions and runoff events, Non-point source, Water quality 


\section{INTRODUCTION}

Over the last few decades, changes in landuse patterns and farming practices, caused by demographic, economic, political and/or cultural mutations, have notable effects on water supply, water quality and soil erosion. As a consequence, water is becoming polluted by nutrients, increasing the eutrophication hazards. Eutrophication is a continuous problem for water resource managers, as it leads to a significant loss of amenity in terms of water supply, fisheries and recreation. In the past, nutrients from point source discharges have been the main contributors. Point sources are now relatively controlled through rules and regulations as they are easy to identify and quantify. However, even though tertiary treatment has become more widespread in controlling point source pollution, the limnological problem has not diminished. Attention has now switched to non-point nutrient sources. In contrast to point sources, the non-point sources such as rural and urban stormwater runoff are difficult to control, as these are diffusive and chronic in nature.

The Yarra River located in Melbourne, Australia has played a key role in the way Melbourne has developed and grown. The forested upper reaches of the river is the source of the city's high quality drinking water. However, the river water quality has degraded in the Middle and Lower Yarra. This has been shown by water quality data collected at most water quality monitoring sites in the catchment, and has not been complying with the State Environment Protection Policy (SEPP) objectives for many years (Melbourne Water and EPA Victoria, 2009). This deterioration in water quality in the Middle and Lower Yarra is a result of agricultural and urban run-off, sewer spills etc. (Melbourne Water, 2010). The major constituent loads affecting this water quality are nutrients (nitrogen and phosphorus) and sediments while others being pathogens, toxicants and litter (Melbourne Water, 2010). This degradation of water quality has prompted a need to assess nutrients and sediment loads in the catchment for development of appropriate management strategies.

Catchment-scale management programs have been proven to be efficient in reducing water pollution from landuse activities. Understanding the connection between land use, land management, and water quality is important in the development of appropriate management strategies of a catchment. However, the lack of information of nutrient and sediment mass loads at various sections of the catchment is a major impediment in applying these management programs. Two major types of water quality models have been developed to estimate the pollutant loadings into the water bodies. These are (1) complex mechanistic models such as SWAT (Arnold et al., 1998), and (2) simple empirical or data-based models such as the regression model LOADEST (Runkel et al., 2004). The estimated pollutant loads can be used in pollutant budget calculations, and to detect trends in water pollution. In addition, information of nutrient and sediment mass loads at various sections of a catchment helps to indentify critical areas responsible for yielding high pollutant loads, and correlation between loads and landuse types.

Mechanistic and data-based models can be applied successfully in different projects of water management program with their specific perspective. Mechanistic models can investigate the specific mechanisms causing surface runoff and pollutant transport. However, they have a number of disadvantages such as a dependence of site-specific parameters; model parameters require additional effort and expense to measure; and the models impose a theory upon the data, a theory that may or may not be complete (Worrall and Burt, 1999a). On the other hand, data-based models are based on the analysis of observations, and seek to characterize response from these data. The computational and data requirements for such models are usually less than for mechanistic models, and are often supported by coarse measurements. Moreover, mechanistic models require observed data for calibration which are usually generated by data-based models using discrete samples. Therefore, an alternative to mechanistic models is to use simple data-based models especially for management use where limited time and data available (Worrall and Burt, 1999b). However, data-based models can only estimate loads for the observed periods and for the existing conditions of the catchment.

The load of a water quality constituent in a stream is a function of concentration of the constituent and stream discharge. The measurement of a pollutant concentration requires water sampling, storing, and costly laboratory analyses, which makes concentration measurement a limiting factor for estimating pollutant loads. Therefore, in most cases, water quality measurements are done sparsely, mainly for compliance purposes. In this case, integrating concentration and streamflow may be inappropriate to calculate the loads. There are different techniques used for load estimation, differing in complexity, accuracy and bias. Existing data-based methods for load estimation can be classified into three major classes: (i) averaging estimators, (ii) ratio estimators, and (iii) regression methods (Marsh and Waters, 2009). The averaging estimators are based on some form of averaging in concentration or flow data. The ratio estimators are based on the ratio of flow and concentration and often modified by a bias correction factor. The regression methods are based on fitting a relationship between flow and concentration for estimating a continuous trace of concentration. Based on the literature, Quilbe et al. (2006) suggested that: (i) averaging estimators are accurate only when concentration measurements are available for the entire flow range; (ii) the ratio estimators are less sensitive to river and 
pollutant characteristics than regression methods but requires more data to achieve the same level of precision; (iii) regression methods can give the best results for sediments and total phosphorus if streamflow and concentration data are strongly correlated for a wide range of streamflow values. Therefore, the regression method should be given priority if the correlation is high enough. Since the temporal variability of the relationship between concentration and streamflow can be very important, some authors proposed to define a regression equation as a function of time in order to take into account non-linearity as well as seasonal and long-term variability (Cohn et al., 1989). Wang et al. (2010) further consider some additional predictors that capture unique features in the flow data which in turn improves the regression models.

Assessing water quality constituents using water samples representing specific flow regimes, i.e., baseflow and events may provide an insight into constituent sources, transport, and potential impact on a river (White et al., 2004). For example, stream water quality during baseflow will be more affected by discrete pollution sources such as municipal wastewater treatment plants, groundwater recharge, and various abiotic and biotic processes within the stream system. Alternatively, water quality during events will be more influenced by resuspension of temporarily retained in-stream constituents and non-point source pollutants entrained by surface runoff during episodic precipitation events. Thus, it is expected to observe difference between constituents and water quality during these flow regimes.

The main objective of this study was to assess nutrient and sediment loads at various sections of the Yarra River catchment in Victoria, Australia for the period of 1998-2009, and to investigate the correlation between these loads and different landuse types. The specific objectives were to: (1) establish whether there is a statistically significant difference between concentrations in water quality samples representing baseflow conditions and surface runoff events, (2) estimate pollutant mass load: nutrients and sediment, and (3) identify the significant and major sources of pollutant loads. The outcome of this study will be helpful to develop appropriate management strategies for the Yarra River catchment, and also will be used to calibrate and validate a complex model, SWAT for the same catchment.

\section{STUDY SITE DESCRIPTION}

The Yarra River catchment has an area of over 4,000 square kilometers. The distance from the head, at the Yarra Ranges National Park, to the end of its estuary, at Port Phillip Bay, is about $245 \mathrm{~km}$, with additional 1,800 $\mathrm{km}$ of named tributaries (EPA Victoria, 1999). About 21 percent of the catchment retains its natural vegetation, 57 percent is agricultural and 22 percent is urbanised. Three distinct segments, namely: Upper, Middle and Lower Yarra segments have been defined for the Yarra River catchment, based on different landuse activities as shown in

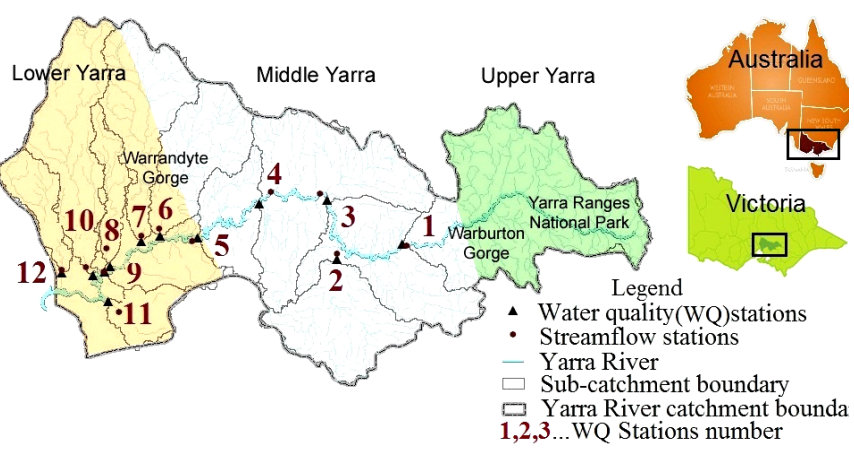

Figure 1. Yarra River catchment

Figure 1. The Upper Yarra segment, from the Yarra Ranges National Park to the Warburton Gorge at Millgrove, consists of mainly dense and extensive forested area with minimum human population. The Middle Yarra segment, from the Warburton Gorge to Warrandyte Gorge, is mainly rural floodplains and valleys with limited urban development. The majority of the surrounding land is used for agricultural purposes. The Lower Yarra segment, downstream of Warrandyte, is mainly urbanised floodplains, and has the poorest water quality. The annual rainfall of the Yarra River catchment varies from approximately 1,600 $\mathrm{mm}$ in the Upper Yarra area to about $600 \mathrm{~mm}$ in the Lower Yarra region ( $\mathrm{Ng}$ et al., 2006). Low flows occur from November to June, whereas high flows occur during other times of the year.

\section{METHODS AND TECHNIQUES}

\subsection{Data Collection and Preliminary Analysis}

The major water quality monitoring program in the Yarra River catchment is the Melbourne Water's monitoring network at 33 stations (St.) on monthly basis along the Yarra River and its tributaries. Among 33 stations, 12 stations were selected representing the Yarra River and its major tributaries of which 5 stations were on the main stem of the Yarra River as shown in Figure 1 and Table 1. Data characteristics (data censored or missing) and period of records also influenced the selection of the stations. Total Nitrogen (TN), Total Phosphorus (TP) and Total Suspended Solids (TSS) data were collected for these 12 stations from 
Melbourne Water for the period of 1998 to June of 2009. These constituents are important for management purposes in the catchment. Melbourne Water sets long-term goals for rivers and creeks in the Port Phillip and Westernport region, Victoria to reduce nitrogen inputs to Port Phillip Bay by 100 tonnes a year by 2010 . Furthermore, all natural rivers and creeks are to be in good or better condition (Melbourne Water, 2010) by 2025. The corresponding daily mean streamflow data were collected from nearby 12 streamflow stations by Melbourne Water. Table 1 shows that the study period is very dry compared to the whole period of record.

Table 1. Monitoring station and streamflow statistics (WQ St. No. corresponds to Figure 1)

\begin{tabular}{|c|c|c|c|c|c|c|c|c|c|}
\hline \multirow{3}{*}{\multicolumn{2}{|c|}{$\begin{array}{l}\text { WQ St. } \\
\text { No. }\end{array}$}} & \multirow{3}{*}{ Water quality (WQ) stations } & \multirow[t]{3}{*}{ Easting } & \multirow[t]{3}{*}{ Northing } & \multirow{3}{*}{$\begin{array}{l}\text { Period of } \\
\text { record }\end{array}$} & \multicolumn{4}{|c|}{ Daily mean streamflow $\left(\mathrm{m}^{3} / \mathrm{s}\right)$} \\
\hline & & & & & & \multicolumn{3}{|c|}{ Study period 1998-2009 } & \multirow{2}{*}{$\frac{\text { Period of record }}{\text { Mean }}$} \\
\hline & & & & & & Min. & Mean & Max. & \\
\hline \multirow{5}{*}{ 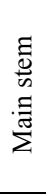 } & 1 & Yarra River at Millgrove & 380712 & 5820934 & $1970-2009$ & 0.709 & 2.87 & 37.14 & 4.51 \\
\hline & 3 & Yarra River at Healesville & 367012 & 5828984 & 1980-2009 & 0.962 & 6.44 & 79.40 & 10.68 \\
\hline & 4 & Yarra River at Coldstream & 354512 & 5828284 & 1991-2009 & 1.346 & 7.89 & 134.59 & 11.58 \\
\hline & 5 & Yarra River at Warrandyte & 343212 & 5821984 & $1970-2009$ & 1.285 & 6.70 & 113.28 & 12.88 \\
\hline & 9 & Yarra River at Kew & 326212 & 5815784 & $1975-2009$ & 1.547 & 8.52 & 218.57 & 13.81 \\
\hline \multirow{7}{*}{ 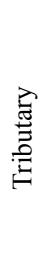 } & 2 & Woori Yallock Creek at Woori Yallock & 368752 & 5818084 & $1975-2009$ & 0.084 & 1.44 & 34.28 & 2.50 \\
\hline & 6 & Diamond Creek at Eltham & 336412 & 5822424 & $1978-2009$ & 0.001 & 0.37 & 91.98 & 0.64 \\
\hline & 7 & Plenty River at View Bank & 333012 & 5821384 & $1977-2009$ & 0.001 & 0.30 & 46.74 & 0.60 \\
\hline & 8 & Darebin Creek at Alphington & 327269 & 5816798 & $1999-2009$ & 0.001 & 0.35 & 50.33 & 0.34 \\
\hline & 10 & Merri Creek at Yarra Bend & 324192 & 5815224 & $1975-2009$ & 0.040 & 0.72 & 106.13 & 1.12 \\
\hline & 11 & Gardiners Creek at Hawthorn & 326912 & 5810384 & $1978-2009$ & 0.001 & 0.56 & 48.28 & 0.76 \\
\hline & 12 & Moonee Ponds Creek at Flemington & 318412 & 5815684 & 1991-2009 & 0.013 & 0.42 & 87.17 & 0.43 \\
\hline
\end{tabular}

A sub-catchment map defining drainage area for each water quality sampling station was generated from ASTER 30m global digital elevation model (http://asterweb.jpl.nasa.gov/gdem-wist.asp) using ArcGIS 9.3 tools. A land cover map (50m grid raster data collected from Bureau of Rural Sciences, Australia) was overlaid and the proportions of major landuses in each sub-catchment were calculated as presented in Table 2. The dominant landuse type in the tributary stations was either agriculture or urban, whereas it was forestagriculture mix type in the main stem stations.

It is also necessary to identify the specific flow Table 2. Percent of major landuses, and baseflow and regimes (i.e., baseflow and events) of the collected water quality sampling and estimated pollutant loads to get an insight into the pollutant sources. Hydrograph separation allows separation of water quality data into baseflow and events. The baseflow data are defined as those water quality data collected when baseflow discharge is greater than or equal to $70 \%$ of mean daily discharge, and events data are defined as those data collected when baseflow discharge is less than $70 \%$ of mean daily discharge (White et al., 2004). Various techniques are available to separate baseflow from streamflow data. These include traditional manual graphical procedures to more recent automated procedures. Several studies have runoff days designated by "Baseflow Filter Program"

\begin{tabular}{|c|c|c|c|c|c|c|c|c|}
\hline \multirow{2}{*}{$\begin{array}{c}\text { WQ } \\
\text { St. } \\
\text { No. }\end{array}$} & \multicolumn{5}{|c|}{$\begin{array}{l}\text { Landuses associated with the WQ } \\
\text { stations }\end{array}$} & \multicolumn{3}{|c|}{ Baseflow and Events } \\
\hline & $\begin{array}{c}\text { Forest } \\
(\%)\end{array}$ & $\begin{array}{l}\text { Agri. } \\
(\%)\end{array}$ & $\begin{array}{c}\text { Urban } \\
(\%)\end{array}$ & $\begin{array}{c}\text { Others } \\
(\%)\end{array}$ & $\begin{array}{l}\text { ainag } \\
\text { area } \\
\left(\mathrm{km}^{2}\right)\end{array}$ & $\begin{array}{c}\text { Baseflow } \\
\text { days }\end{array}$ & $\begin{array}{l}\text { Events } \\
\text { days }\end{array}$ & $\begin{array}{c}\% \text { of } \\
\text { Events } \\
\text { days }\end{array}$ \\
\hline \multirow{5}{*}{ 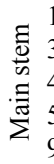 } & 64 & 35 & 0 & 1 & 844 & 3560 & 639 & 15 \\
\hline & 50 & 44 & 6 & 0 & 1566 & 3450 & 749 & 18 \\
\hline & 49 & 44 & 7 & 0 & 2153 & 3515 & 684 & 16 \\
\hline & 46 & 43 & 10 & 1 & 2354 & 3412 & 787 & 19 \\
\hline & 38 & 43 & 18 & 1 & 3323 & 3262 & 937 & 22 \\
\hline \multirow{7}{*}{ 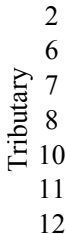 } & 33 & 49 & 18 & 0 & 326 & 3462 & 737 & 18 \\
\hline & 26 & 49 & 25 & 0 & 309 & 2663 & 1536 & 37 \\
\hline & 24 & 53 & 21 & 2 & 351 & 2778 & 1411 & 34 \\
\hline & 3 & 52 & 44 & 1 & 105 & 2443 & 1240 & 34 \\
\hline & 2 & 67 & 31 & 0 & 392 & 2960 & 1239 & 30 \\
\hline & 0 & 0 & 100 & 0 & 107 & 2645 & 1554 & 37 \\
\hline & 9 & 36 & 49 & 6 & 125 & 3019 & 1180 & 28 \\
\hline
\end{tabular}
shown that the automated digital filter technique compares well to manual and other automatic baseflow separation techniques and with measured results (Arnold et al., 1995). In this study, baseflow was separated using automated digital filter based software "Baseflow Filter Program" (USDA-ARS, 1999). Each day was then designated to be either baseflow or events as shown in Table 2. The percent of events days in the main stem stations was less than in the tributary stations.

After categorising water quality data into baseflow or events, summary statistics were calculated to describe the two concentration data sets for each constituent including maximum, minimum, median, and mean values. Then the Mann-Whitney rank-sum and Kruskal-Wallis test (White et al., 2004) were used to determine statistically significant differences between baseflow and events concentrations at each station and among different stations respectively using SPSS 18 statistical analysis software. These tests compare the median concentrations from the independent groups of data. These tests were selected because they do not require normally distributed data, and are also applicable in case of censored data (Helsel and Hirsch, 1992). 


\subsection{Estimation of Pollutant Loads and Yields}

Before applying any data-based water quality model, the correlations between streamflow and concentrations of TN, TP and TSS were determined at all water quality stations. On the main stem of Yarra River, the correlation of TN was 0.6-0.8, and that of TP and TSS was 0.5-0.8 with the exception of TP at St. No. 3, 9 and TSS at St. No. 3, 4. Similarly, on the tributaries, the correlations of TN, TP and TSS were 0.4-0.7, 0.40.8, and 0.5-0.9 respectively with exception of TN at St. No. 11, 12 and TP at St. No. 2, 11. In general, all the correlations were found to be significant at 0.01 level. Therefore, a regression based model LOADEST (Runkel et al., 2004) was used to estimate the pollutant loads in this study. The LOADEST model was developed by the U.S. Geological Survey to estimate the constituent loads in streams and rivers. The LOADEST model evaluates the relationships between pollutant loads, and streamflow and time variables to consider time trend and seasonal trend based on eleven predefined models or a user-defined model. The users can select a model manually or automatically based on lowest value of AIC (Akaike, 1974). For example, the seven-parameter model is given below;

$\ln (\mathrm{L})=\mathrm{a}_{0}+\mathrm{a}_{1} \ln \mathrm{Q}+\mathrm{a}_{2} \ln \mathrm{Q}^{2}+\mathrm{a}_{3} \sin (2 \pi \mathrm{dtime})+\mathrm{a}_{4} \cos (2 \pi \mathrm{dtime})+\mathrm{a}_{5} \mathrm{dtime}+\mathrm{a}_{6} \mathrm{dtime} \mathrm{e}^{2}$

Where $\ln =$ natural logarithm; $\mathrm{L}=$ pollutant load in $\mathrm{kg} /$ day; $\mathrm{a}_{0}=$ regression constant; $\mathrm{a}_{1}, \mathrm{a}_{2}, \mathrm{a}_{3}, \mathrm{a}_{4}, \mathrm{a}_{5}, \mathrm{a}_{6}=$ regression coefficients; $\mathrm{Q}=$ daily mean streamflow in $\mathrm{ft}^{3} / \mathrm{s}$; dtime = time parameter in decimal years. LOADEST analysis showed that data from all stations generally fit the models well. The models were developed for the whole study period at each water quality station. The best model was selected automatically in LOADEST based on AIC. Adjusted maximum likelihood estimation and calibration option was selected in LOADEST as residuals approximated a normal distribution, and sometimes contained censored data. Figure 2 shows plotting of residuals against explanatory (streamflow and time) and predicted variables (estimated load) at Coldstream station (St. No. 4) as a typical case for TN; they were reasonably homoscedastic. Similarly, the goodness of fit in the estimation was also tested by normal probability plot of the residuals, and found to be normally distributed as shown in Figure $2 \mathrm{~d}$.
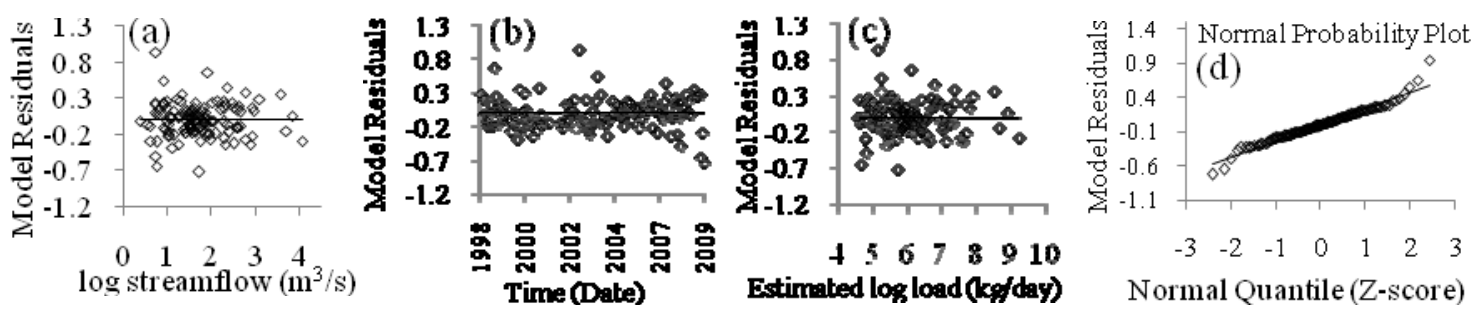

Figure 2. Model residuals against (a) explanatory (b) explanatory and (c) predicted variables, and (d) normal probability plot for TN at Coldstream station (St. No. 4)

The coefficients of determination $\left(\mathrm{R}^{2}\right)$ for the models were evaluated for model performance. The $\mathrm{R}^{2}$ values for all pollutants at all stations were greater than $85 \%$ except for TP and TSS at two stations (St. No. 1 and 10). Figure 3 shows a typical case of comparison between observed and estimated TN loadings at Coldstream station. Obseved loads were calculated on a particular sampling day by multiplication of mean daily streamflow and pollutant concentration. LOADEST generates daily loads for each day of the study period for all the pollutants. The daily loads were then categorized into baseflow and events load sets according to the number of baseflow and events days in the study period. Estimated mean annual baseflow loads were then calculated as the mean of the baseflow load set. Estimated mean annual events loads were calculated as the mean of the events load set. Moreover, TN, TP and TSS yields were calculated by dividing

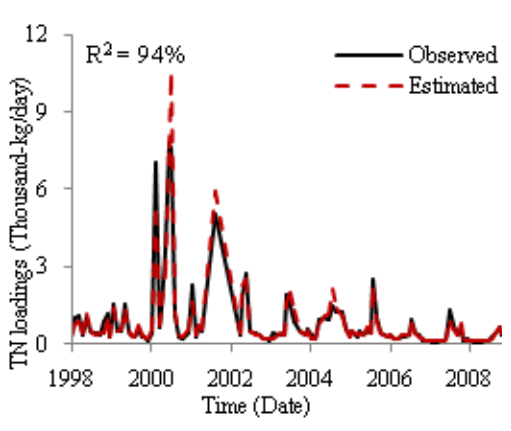

Figure 3. Observed versus estimated $\mathbf{T N}$ loadings their mean annual loads by the corresponding station drainage area.

\section{RESULTS AND DISCUSSION}

\subsection{Pollutant Concentrations}

Statistical analysis (maximum, minimum, median, and mean) showed that nutrient (TN and TP) concentrations were greater in tributaries than in main stream stations, and increased from upstream to downstream of the catchment. This indicates that nutrient concentrations are higher in urban and agricultural 
regions than in forest regions of the catchment (see Table 2). However, TSS concentrations did not follow the above trend. At all stations, the TN, TP and TSS baseflow mean concentrations (also known as dry weather concentration, DWC) were $1.18,0.07$ and $11.75 \mathrm{mg} / 1$ respectively, and events mean concentrations (EMC) were $1.55,0.11$ and $34.67 \mathrm{mg} / \mathrm{l}$ respectively. The Mann-Whitney rank-sum test results showed that TN, TP and TSS concentrations were significantly greater $(\mathrm{p} \leq 0.01)$ in events than in baseflow at all stations except TN at St. No. 2, 6 and 12. Also, the Kruskal-Wallis test results showed that TN, TP and TSS concentrations were significantly greater $(\mathrm{p} \leq 0.01)$ in urban dominated areas (St. No.11) than in agricultural dominated areas (St. No.10), and further in agricultural dominated areas than in forest dominated areas (St. No.1).

Figure 4 shows pollutant concentrations in baseflow and events at Coldstream station as an example. TN, TP, and TSS concentrations in events generally increased with streamflow at all stations. However, TP concentrations at the main stem and TSS concentrations at any stations did not increase with streamflow in baseflow. Possible causes of larger concentrations of TN, TP and TSS in events are the addition of the constituents from nonpoint sources, resuspension of nutrients from the streambed sediment, and stream bank erosion. Wagner and Woodruff (1997) reported similar findings in their study.
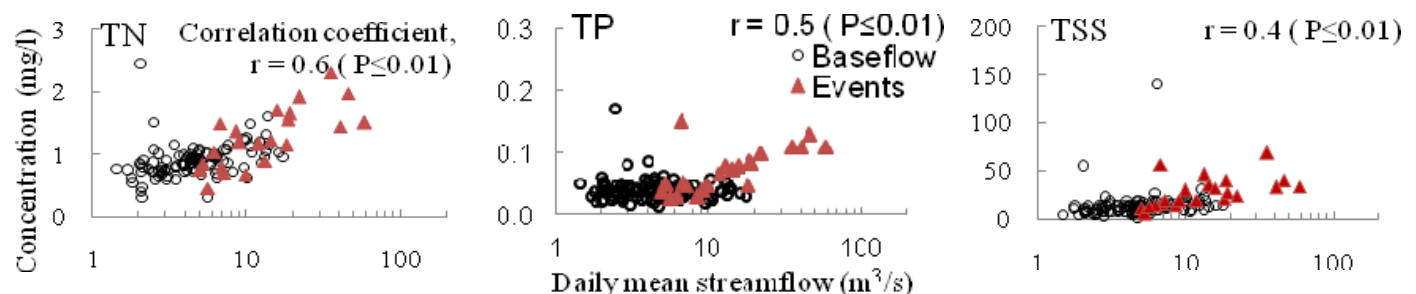

Figure 4. Pollutant concentrations in baseflow and events at Coldstream station (St. No. 4)

\subsection{Estimated Mean Annual Loads and Yields}

In general, the mean annual TN, TP and TSS total loads increased from upstream to downstream at the main stem stations of the catchment, with the annual total loads at the Kew station (St. No. 9) about 6, 10 and 12 times that of Millgrove station (St. No. 1) for TN, TP and TSS respectively.

The mean annual TN, TP and TSS events loads and events yields increased from upstream to downstream, but its intensity significantly depended on landuse types. Figure 5a shows that the relative proportion of events load into the total load is much higher in the tributary stations than in the main stem stations as a typical case for TN, and Figure 5b shows this in case of yields as well. This is expected because tributary stations are either dominantly agriculture or urban types where as main stem stations are forest-agriculture types (Table 2). TN, TP and TSS loads delivered during events at all main stem stations were on average 49, 54 and 64 percent of the total loads respectively where events days were on average 18 percent during the study period (Table 2). On the other hand, the events loads for TN, TP and TSS at the tributary stations were on average 79, 81 and 91 percent respectively where events days were on average 31 percent. Also, TN, TP and TSS events yields from agriculture dominant area (St. No.10) were about 3,8 and 8 times respectively higher than that of forest dominant area (St. No.1). TN, TP and TSS events yields from urban dominant area (St. No.11) were about 13, 33 and 42 times respectively higher than that of forest dominant area (St. No.1)

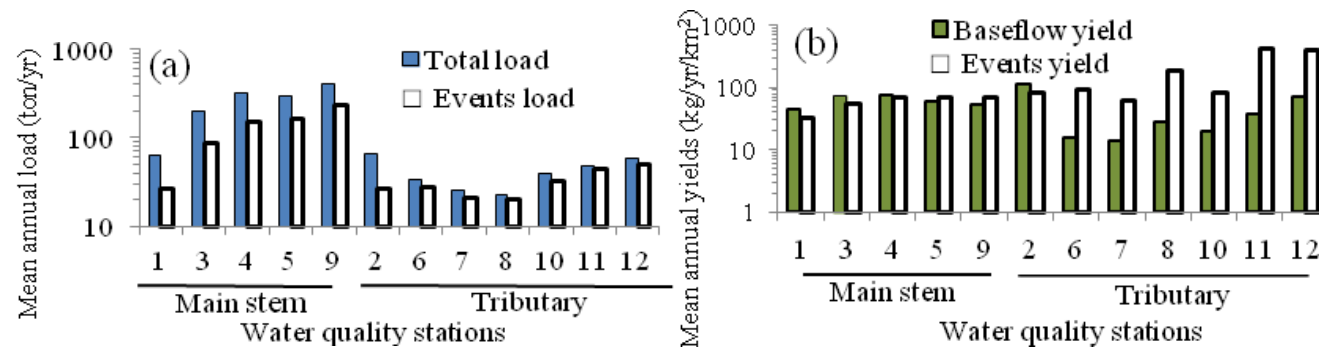

Figure 5. Mean annual (a) total and events loads and (b) baseflow and events yields for TN

The estimated mean annual TN, TP and TSS total loads at the outlet of the catchment were about 553, 42 and 29,404 tons per year respectively. About 65,69 and 86 percent of these annual TN, TP and TSS total loads respectively were delivered by events, although the study period is dry compared to the period of record (Table 1). Moreover, higher percentage of TN (49\%) was generated from middle agricultural segment, and TP (51\%) and TSS (60\%) were from lower urban segment, but any pollutant from upper forest segment was less than $12 \%$ of the catchment total outlet loads. These evidenced that major pollutant loads were generated from agricultural and urban runoff (i.e., non-point sources). 


\section{CONCLUSIONS}

The nutrient and sediment loads in the Yarra River catchment has been assessed in this study by a simple generic method using long-term in-stream water quality data and other readily available tools. A data-based model was applied to estimate constituent loads (i.e., TN, TP and TSS) rather than a complex mechanistic model. Although the methodology does not indicate the specific mechanisms causing surface runoff and pollutant transport, the data-based model is simple to apply and leads to good results, particularly in circumstances where limited time and data are available.

At all stations, the constituent concentrations were significantly $(\mathrm{p} \leq 0.01)$ greater in events than in baseflow. The major conclusion from this study was that major pollutant loads were generated from non-point sources during events. Overall, water quality and constituent concentrations were influenced by flow conditions and landuse types. The presence of increasing nutrients and sediment concentrations during events suggests that Yarra River catchment managers should focus on potential non-point sources that occur during precipitation events and surface runoff conditions in streams.

\section{ACKNOWLEDGMENTS}

The authors wish to thank Melbourne Water, Bureau of Rural Sciences (Australia), U.S. Geological Survey and NASA-Japan government for providing data and tools for this project.

\section{REFERENCES}

Akaike, H. (1974). A new look at the statistical model identification, IEEE Transactions on Automatic Control, 19(6), 716-723.

Arnold, J.G., Allen, P.M., Muttiah, R. and Bernhardt, G. (1995). Automated base flow separation and recession analysis techniques, Ground Water, 33(6), 1010-1018.

Arnold, J.G., Srinivasan, R., Muttiah, R.S. and Williams, J.R. (1998). Large-area hydrologic modeling and assessment: part I. model development, American Water Resources Association, 34(1), 73-89.

Cohn, T.A., Delong, L.L., Gilroy, E.J., Hirsch, R.M. and Wells, D.K. (1989). Estimating constituent loads, Water Resources Research, 25(5), 937-942.

EPA Victoria (1999). Policy impact assessment: protecting the environmental health of Yarra catchment waterways, Report No. 654, Melbourne, Australia.

Helsel, D.R. and Hirsch, R.M. (1992). Statistical Methods in Water Resources, pp.522, Elsevier, Netherlands.

Marsh, N. and Waters, D. (2009). Comparison of load estimation methods and their associated error, in R.S. Anderssen, R.D. Braddock and L.T.H. Newham (eds), The 18th World IMACS Congress and MODSIM09 International Congress on Modelling and Simulation, Cairns, July 13-17, pp.3322-3328.

Melbourne Water (2010). Our Yarra, (http://ouryarra.melbournewater.com.au/content/river_health. Accessed in August 2010)

Melbourne Water and EPA Victoria (2009). Better bays and waterways - a water quality improvement plan for the Port Phillip and Westernport Region: Appendices, pp.45, Melbourne, Australia.

Ng, A.W.M., Perera, B.J.C. and Tran, D.H. (2006). Improvement of river water quality through a seasonal effluent discharge program (SEDP), Water, Air, and Soil Pollution, 176(1), 113-137.

Quilbe, R., Rousseau, A.N., Duchemin, M., Poulin, A., Gangbazo, G. and Villeneuve, J.P. (2006). Selecting a calculation method to estimate sediment and nutrient loads in streams: application to the Beaurivage River (Quebec, Canada), Journal of Hydrology, 326(1-4), 295-310.

Runkel, R.L., Crawford, C.G. and Cohn, T.A. (2004). Load Estimator (LOADEST): A FORTRAN program for estimating constituent loads in streams and rivers, pp.69, US Geological Survey Techniques and Methods Book 4, Virginia, Chapter A5.

USDA-ARS (1999). Soil and Water Assessment Tool, SWAT: Baseflow Filter Program (Available at http://swatmodel.tamu.edu/software/baseflow-filter-program. Accessed in May 2010).

Wagner, K. and Woodruff, S. (1997). Phase I clean lakes project, diagnostic and feasibility study of lake Eucha, pp.63, Oklahoma Conservation Commission, U.S.A.

Wanga, Y.G., Kuhnert, P. and Henderson, B. (2010). Load estimation with uncertainties from opportunistic sampling data - a semiparametric approach, Journal of Hydrology, 396(1-2), 148-157.

White, K.L., Haggard, B.E. and Chaubey, I. (2004). Water quality at the Buffalo national river, Arkansas, 1991-2001, Transactions of the American Society of Agricultural Engineers, 47(2), 407-417.

Worrall, F. and Burt, T.P. (1999a). A univariate model of river water nitrate time series, Journal of Hydrology, 214(1-4), 74-90.

Worrall, F. and Burt, T.P. (1999b). The impact of land-use change on water quality at the catchment scale: the use of export coefficient and structural models, Journal of Hydrology, 221(1-2), 75-90. 